\title{
Comparative Study of Environmental Friendly Concept on Fashion in Indonesia
}

\author{
Arini Arumsari ${ }^{1}$, Agus Sachari ${ }^{2}$, Andryanto Rikrik Kusmara ${ }^{3}$ \\ ${ }^{1}$ School of Creative Industries, Telkom University, Bandung, Indonesia \\ ${ }^{2}$ Faculty of Art and Design, Institut Teknologi Bandung, Bandung, Indonesia \\ 3 Faculty of Art and Design, Institut Teknologi Bandung, Bandung, Indonesia \\ ariniarumsari@telkomuniversity.ac.id (Arini Arumsari), asachari@yahoo.com (Agus Sachari), rikrik1212@yahoo.com (Andryanto \\ Rikrik Kusmara)
}

\begin{abstract}
Rapid development of fashion industry in Indonesia provides good opportunities and potentials for fashion products in Indonesia, where at a closer look, it is also provides bad impacts to wards the environment and community. The bad impacts come from the usage of non-eco-friendly materials, industrial waste that is not optimally processed, low quality product with short lifetime cycle, manpower issues, and so on.
\end{abstract}

To cope with the bad effects, an eco-friendly fashion concept is created by using several terms such as: sustainable fashion; eco-fashion, ethical fashion or organic fashion. Those terms are gained from previous researches performed by the researcher herself and other references and researches. Result of the research shows that many terms are found to refer to a fashion development concept with environmental awareness. Therefore, based on the finding above and to optimize the implementation of fashion concept with environmental awareness on fashion industry in Indonesia, firstly, it needs meticulous and comprehensive identification and elaboration towards various terms of the said concept.

To get comprehensive data for this research, qualitative method is performed through literature study, observation, and interview. It is expected that the final result will provide a proper direction to implement the fashion concept with en vironmental awareness on fashion industry in Indonesia.

Keywords: fashion industry, ethical fashion, eco-fashion, sustainable fashion, organic fashion

\section{Introduction}

Fashion industry in Indonesia develops rapidly nowadays, fashion as one of creative industry sub-sectors has taken a big part of the industry compare to other sub-sectors. Its related data can be found in a book titled Buku Pengembangan Ekonomi Kreatif Indonesia 2025 printed by the Department of Trade of Indonesia.

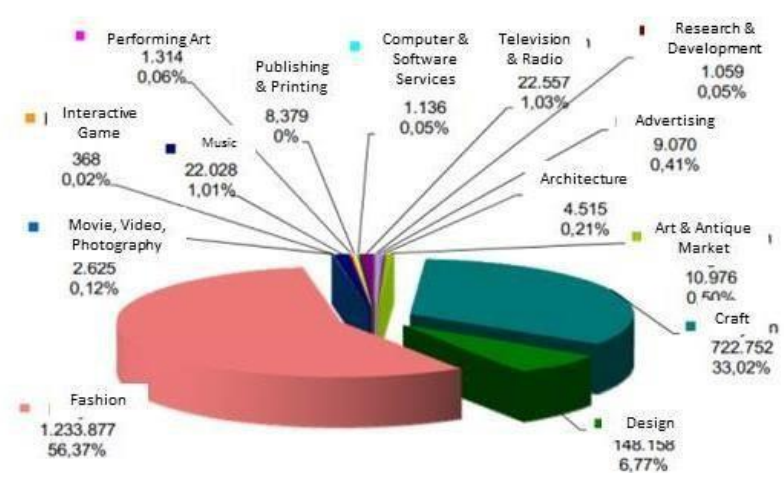

Figure 1. Fashion Industry Development in Indonesia (Source: Buku Pengembangan Ekonomi Kreatif Indonesia 2025: Department of Trade of Indonesia)

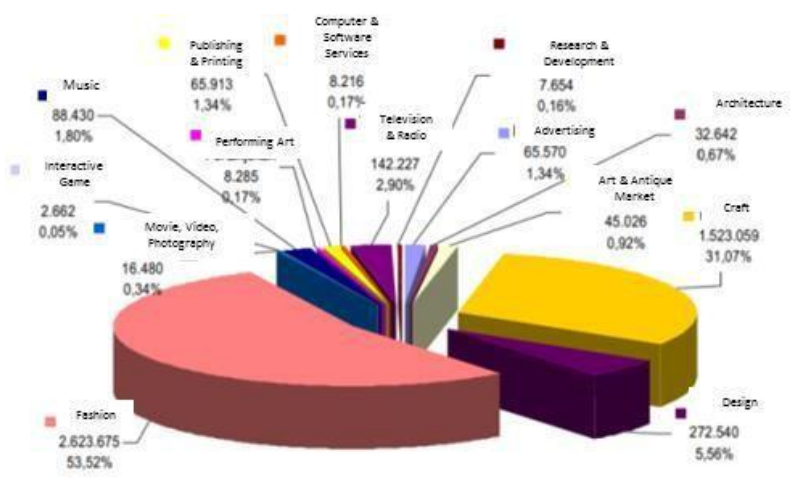

Figure 2. Fashion Industry Development in Indonesia (Source: Buku Pengembangan Ekonomi Kreatif Indonesia 2025: Department of Trade of Indonesia)

The rapid development of fashion industry in Indonesia provides good opportunities and potentials for fashion products in Indonesia, where at a closer look, it is also provides bad impacts towards the environment and community. The bad impacts come from non-eco-friendly materials us- 
age, industrial waste that is not optimally processed, low quality product with short lifetime cycle, social manpower issues, and so on.

Result of previous research shows that many terms are found to refer to a fashion development concept with environmental awareness which has been improved by many fashion parties such as practitioners, industrial actors, re-searchers, or national and international academics. Based on the data, the reason why many parties improve the eco-friendly fashion concept in Indonesia is because there is a huge urgency to get the community and various involved parties to be aware on the possible bad effects of fashion industry may occur if it is allowed to be developed without having the eco-friendly awareness. Terms that are frequently used to refer to ecofriendly fashion concepts are sustainable fashion, eco-fashion, ethical fashion atau organic fashion.

\section{Main Body}

To elaborate all concepts that discuss the eco-friendly development in fashion, in order to be focused and get a proper direction of discussion, therefore, concepts will be discussed is from that is global to that is specific in fashion. Diagram of the discussion order is as follows:

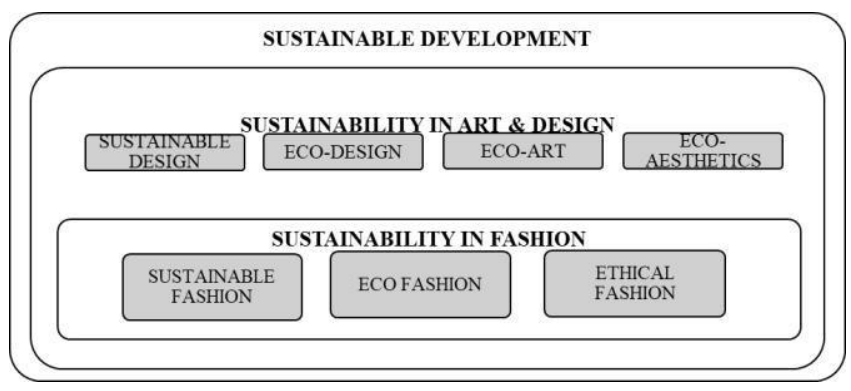

Figure 3. Diagram of Discussion Sequences

First concept will be discussed is the most global one that covers various fields including fashion, i.e. sustainable development. This concept is discussed to be the initial fundamental of eco-friendly concept on more specific fields. Sustainable development is an effort to react to the environmental crisis occurs in many parts of the world as the impact of construction works and industry. Eventhough construction works have provided environmental crisis, however it cannot be terminated directly, since it effects to the community's welfare. So that, according to Muhammad Akib in his book Penegakan Hukum Lingkungan (2015), it is mentioned that the most rational option is to continue the construction works, but with a different set of mind paradigm. Environmental sustainable paradigm shall be an option and integrated in the construction planning. The said paradigm shall also be the mindset of all interested parties, including bureaucrat, law enforcer and the community. The construction concept is known as an environmental and sustainable construction policy.

Definition of environment, in Law No. 23 of 1997 Article 1 clause 1 concerning environmental management, is the spatial unity of all materials, forces, situations, and living creatures, including humans and their behavior, which in- fluences the continuance of the life and welfare of humans and other living creatures.

According to Supardi (2003), environment is all living and inanimate objects as well as all circumstances that exist in a space we are living. In general, environment comprises physical or abiotic environment and biotic environment. Abiotic environment is all inanimate objects and physical condition surround individuals such as rocks, mineral, water, climate elements, humidity, wind and so on. These physical environment has a close relationship with the living creatures reside there, such as mineral contained in the soil determines its fertility which is also has a close relationship with the plants grow on its surface. Biotic environment is all the living creatures surround individuals either human, animal or plants. In more global, discussion and direction regarding this sustainable development has frequently performed by the United Nations and its subentities.

Discussions in form of general assembly, conference, and symposium by the United Nations are as follows:

1. In the United Nations' General Assembly in 1987 entitled "Our Common Future", WCED gives definition of sustainable development as: "a development that meets the needs of the present without comprimising the ability of future generations to meet their own needs."

2. In Rio de Janeiro Earth Summit on the $3^{\text {rd }}$ to $14^{\text {th }}$ of June, 1992 resulted Rio Declaration. The Declaration contents: "The right to development must be fulfilled so as to equitably meet developmental and environmental needs of present and future generations". From this formula, it is explained that the essential and philosophy of sustainable development fundamentally wishes to manifest an integration between environment and building to fulfill present and next generations needs.

3. 5 main principles of sustainable development resulted from UNCED in Rio de Janeiro, i.e.:
a. Intergenerational equity
b. Intragenerational equity
c. Precautionary
d. Conservatorial of biological diversity
e. Internalization of environmental costs

4. In 2007, UN Climate Change Conference was held in Bali, a meeting to discuss world climate change, including the possibility of Kyoto Protocol amendment.

5. $3^{\text {rd }}$ UNESCO World Forum on Culture and Cultural Industries, with a topic of: "Culture, Creativity and Sustainable Development Research Innovation Opportunities" was held in Florence, Italia on the $2^{\text {nd }}$ to $4^{\text {th }}$ of October, 2014.

6. The United Nations created a more specific direction in form of 17 objectives and 169 targets of Sustainable Development in "Transforming Our World: The 2030 Agenda for Sustainable Development" on September 2015

Based on the global guidances, Indonesia has made several law instruments to support the sustainable development, i.e.: Environmental Protection and Management Plan 
(Rencana Perlindungan dan Pengelolaan Lingkungan Hidup (RPPLH)); Study of Environmental strategies (Kajian Lingkungan Hidup Startegis (KLHS)); environ-mental permits; Drafting an Environmental Impact Analysis (Analisis Mengenai Dampak Lingkungan (AMDAL)); environmental quality standard; criteria of environmental damage standard; and economic instruments (such as environmental tax and retribution) and environmental audit.

Next concept will be discussed is a more specific concept of art and design. It is sustainable and eco-design. In general, to perform Eco-Sustainable Design, methods to take are as follows:

1. Eco-Redesign: by identifying and reducing negative environmental impact of existing product or process

2. Eco-Sustainable Innovation: by developing product or new method, which has been concerning environment and social factor from the beginning

3. Sustainable System Innovation, Sustainable Product Service System: by finding system or service that offers a long term value as well as to avoid environmental and social problems."

Strategy to perform Eco and Sustainable Design is as follows:

1. Re-Newable

a. It must use renewable raw material and energy, either in its production process, life cycle, consumption or waste

b. Uses solar or wind energy inside the building and electric-power system

2. Efficient

To reach efficiency in making design product it shall perform:

a. Dematerilizing in terms of material and energy.

b. Optimizing benefit and multifunction.

c. Improving product's durability and age.

d. Utilizing concept of 'instead of owning'. What is implemented on public transportation or what is used collectively is one sample.

3. Safe or non-toxic

Final product shall not contain or produces any hazardous substance or material towards environment and humans by uses replacement material instead of regular material

4. Cyclic

The product shall have continued life cycle, either in terms of material or production technique. Material that is processed shall result minimum waste, even, it can be used for other benefit with good quality.

Product cycle repair comprises:

1. Reusing, Recycling and Upgrading.

This method is performed to re-use the product, re-cycle it and improve its quality.

2. Design for Disassembly.

This method is performed to make knockdown product.

3. Using Renewable Materials.
This method is performed to use renewable materials.

4. Waste Equals Food.

In this method, waste is not perceived as useless material, instead, it is used as raw material to process new product.

5. Social

The final product is used for social activity, such as:

a. To perform campaign for humanity or to promote trading commodity from poverty area.

b. To make good quality product for the poor.

After sustainable design and eco-design, next ecofriendly concepts will be discussed are still in art and design field, i.e. eco-art and eco-aesthetics. Eco-art is in-separable from an understanding of Environmental Art. A practitioner of eco-art named Aviva Rahmani, says that eco-art is an art implementation, where the artist colaborates with scientist, urban planner, architect, and other professionals, togetherly take part to solve environmental deg-radation or problems, if any. (Marianto, Dwi: 2015)

Other definition of eco-art explains that eco art is an artistic work or discipline to propose a mindset, and aware-ness upon various living forms and sources on earth. The objective is to trigger awareness, dialog, change behavior and appreciate natural systems where we live side by side with.

Still according to M Dwi Marianto in her "Art \& Levitation: Seni dalam Cakrawala Quantum", an eco-artist, is one who has done one or more of below things as follows:

1. Concerns interconnection network of various environmental aspects, such as physical, biological, cultural, political and historical aspects of interconnected ecological systems.

2. Creates product that uses natural material or strongly focus on natural powers such as water, wind and solar light.

3. Reclaims, restores, remidies damaged environments.

4. Informs the community regarding ecological dynamics and environmental problems we deal with.

5. Reviews ecological relationships, to creatively prioritize new possibilities for co-existence of sustainability and recovery.

A discussion of eco-aesthetics has been performed by Malcom Miles in his book titled Eco-aesthetics: Art, Literature and Architecture in a Period of Climate Change (2014), Miles says that his book is a discussion of ecology and aesthetics section. However, Miles himself has not yet suggested a terminology of ec-aesthetics as a branch or specialism in philosophy of science. It is mentioned that aesthetics is 'expanded art', i.e. art is a broad field. So that it is possible if art interacts or colaborates with other disciplines. It occurs because art has correlation with how the world is perceived as a perception of subject and object. Therefore, these correlation between subject and object possibly becomes the key to ecology approach that triggers 
aesthetics problem. In the book, Miles also says about the initial idea of "art for greener world", even though he admits that the idea is too naif. Since corelation between art, politic, social and economic changes, are not direct nor causal in nature. Art may not be able to save the planet earth, but art can represent critic and problem that the planet deal with, imaginatively. Art and culture is inseparable from politic, economy, and social system and condition of which art is not merely created as that sort of context. Therefore, it needs historical investigation of art and culture in a certain period of time to get an understanding of the conditions.

There are several large-scaled-international art exhibitions that shows numbers of expansion of art towards other fields, especially in response to ecological, environmental and cultural issues. The exhibitions are as follows:

1. Natural Reality.

This exhibition was held in Stuttgart in 1989. Curated by Heike, considered that environmental damage was caused by human as the subject who perceived and treated nature as object. While in reality, humans and nature live sustainably, and this was what represented in this exhibition. Artists involved in this exhibition were Alba d'Urbano, Ana Mendietta, Madelaine Dietz, Mark Dion, Robert Smithson and Joseph Beuys

2. Groundworks.

This exhibition was held in Pittsburgh in 2000. Curated by Grant Kster by compiling documentations of art products from particular sites which is made in response to a community's location of an urban area which was deindustrialized.

3. Radical Nature.

This exhibition was held in Barbican Art Centre, London in 2006. The objective of this exhibition was as a retrospective of a recreational art product from Agens Denes, Joseph Beuys, Richard Beuckninst Fuller, Hans Haacke and Ivan Morrison from 1969 to 2009.

Discussion of next eco-friendly concept is more specific get into fashion, i.e. eco-fashion and sustainable fashion. According to Gini Stephens Frings in her book Fashion From Concept to Costumer, it is explained that from its basic concept, fashion is defined as follows: "fashion is a reflection of the social, political, and economic and artistic forces of any given time" (Frings, 1987)

So that, definition of fashion is not merely covers clothes design, production and its consumption within the community, but it is more global and crucial in nature. And in this fashion dynamics, in global, a phenomenon in fashion which becomes the evidence of social, politic, economic circumstances reflects and artisctic power that develops nowadays is eco-fashion. Eco-fashion or in several literature is called sustainable fashion.

According to Sandy Black in her book 'The Sustainable Fashion Handbook' regarding sustainable fashion, i.e.: "Sustainable fashion reflects the interdisciplinary nature of fashion's complex ethical and ecological dimensions - as manifested in the production, consumption, marketing and representation of fashion - which often conflicting priorities that need to be reconciled. (Black, 2012)

Based on the definition of sustainable fashion above, therefore, discussion and object selection is performed based on the most comprehensive sustainable fashion scopes that cover production process, consumption, marketing, and representation of the fashion brand or product. Since there are many fashion industries or products claim as sustainable fashion actors, but steps taken are not entirely in accordance with sustainable fashion process.

According to Sass Brown in her book Eco-fashion (2010), definition and scopes of sustainability in design are as follows:

1. Sustainability is a life conservation through ecological balance between humans, animals, plants, and planets.

2. Sustainable design in fashion means that the fashion source and product shall not result pollution and shall not drain non-renewable resources in its process or production, either towards the planet or human.

3. It also refers to clothes or fashion that is able to be reabsorbed by the environment when it reaches its life cycle limit.

From the same source, it is also mentioned that methods are possibly performed are:

1. Community \& fair trade

2. Ecological \& slow design

3. Recycle, reuse \& redesign

4. New models

5. Designer \& corporate initiatives

Meanwhile, according to Jennifer Farley Gordon \& Colleen Hill in their book Sustainable Fashion, Past Present and Future (2015) definition and scopes of sustainable fashion are:

1. Definition of sustainable concept in general refers to an ecological system that is designed to maintain balance, which means there is nothing shall be taken from the renewable environment.

2. "Sustainable" frequently used with other words alternately such as "eco", "green", and "organic"

From the same source, there are methods can be used, i.e.:

1. Repurposed \& recycle clothing and textiles

2. Quality of craftsmanship

3. Material origins

4. Dyeing process

5. Labor practices

6. Treatment of animals

Along with several references above, according to Kate Fletcher in her book Sustainable Fashion and Textile, Design Journeys (2014), scopes of sustainability concept in fashion comprise:

1. Sustainable Fashion \& Textile Products
a. Material Diversity
b. Etchically Made
c. Use Matters
d. Reuse, Recycling and Resource Exchange 
2. Sustainable Fashion and Textile System
a. Fashion, Needs and Consumption
b. Local and Light
c. Speed
d. User Maker

Scope of "sustainable" concept and its diffences with "eco" concept is explained clearer by Kristel Dewulf as follows:

"Sustainable Product Design (SPD) is more than Ecodesign, as it integrates social and ethical aspects of the product's life cycle alongside environmental and economic considerations, aiming for the so-called 'triple bottom line'. Sustainable product development and design is concerned with balancing economic, environmental and social aspects in the creation of products and services."

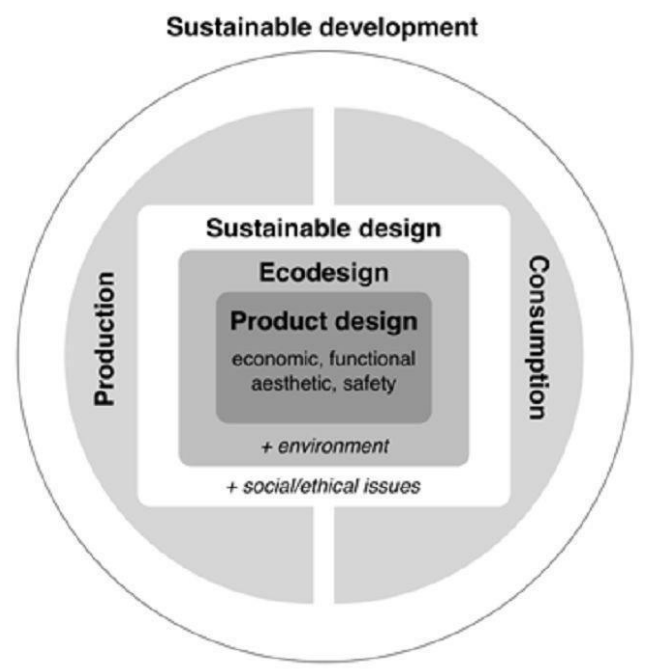

Figure 4. Correlation between eco-design, sustainable design and sustainable development

(source: Paper of Sustainable Product Innovation: The Importance of the Front-End Stage in the Innovation Process oleh Kristel Dewulf, 2013)

Based on the mapping of correlation of product design ecodesign - sustainable design and sustainable development by Kristel Dewulf above, it can be concluded that in general, convensional product or design contains economic, functional, aesthetics and safety values, where if eco-friendly values (environmental issues) is added to the said values, it becomes ecodesign. Further, if it is added by social or ethic values, it becomes sustainable design. So that, in sustaina-ble design there are values of economic, functional, aes-thetic, safety, and comfort that shall be fulfilled by all de-sign products.

Further discussion is regarding ethical fashion. Ethic design can be used as a fundamental for ethical fashion, as has been explained by Victor Papanek as follows:

It's the connection between the spiritual in design and the intent of the designer. To think dispassionately about what we design and why, as well as what the eventual consequences of our design intervention may be, is the basis of ethical thinking. Linked between values, creativity, beauty, art and the transcendental. (Papanek: 1995)

While according to Kate Fletcher in her book Sustaina- ble Fashion and Textxiles, a product is ethically-made qualified-product when it takes responsibility towards environment as well as has concern on social justice towards hu-man, nature and animal. Therefore, ethical fashion concept is influenced by several factors of economic, government, local authority, as well as local culture.

\section{Conclusion}

Various eco-friendly concepts of the design-art and fashion will be elaborated, compared, and made section from various theories, if possible. The objective is to clarify and determine which is the most comprehensive and correct eco- friendly design concept to be applied as the fundamentals in developing eco-friendly fashion brand in Indonesia which fits with social-cultural situations of the community, that has typical and authentic cultural characteristic. Therefore, new theory regarding implementation of eco-friendly fashion is expected to find on fashion brand design in Indonesia that is different with other theories from the Western countries. The said theory or formula can be developed to be a product design strategy in fashion brand to deal with environmental bad impacts issues which will appear if fashion industry in Indonesia is allowed to be rapidly grow without eco-friendly concept.

Based on the comparison study of eco-friendly design concepts in fashion, which has been put in order from the most global to the most specific concepts, therefore, a conclusion of comparison analysis and correlation of ecofriendly concepts in fashion is stated in below diagram.

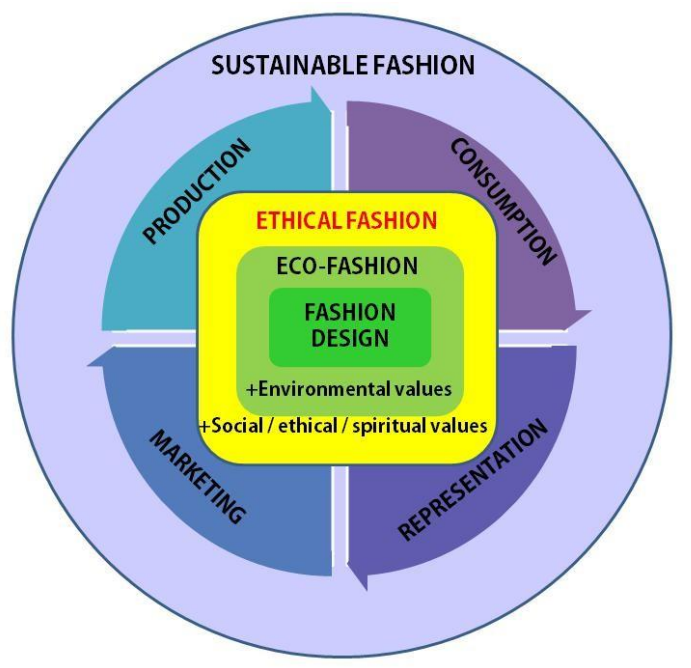

Figure 5. Diagram of correlation between ethical fashion with ecofashion and sustainable fashion.

At the end of this research, eco-friendly concept that researcher refers to is emphasizing on "Ethical Fashion" concept. This concept is selected, instead of other concepts such as "Eco-Fashion" or "Sustainable Fashion", because based on data collecting and analysis have been performed, this "Ethical Fashion" concept is the most representable ecofriendly concept for Indonesia.

It is according to Victor Papanek, "it's the connection between the spiritual in design and the intent of the designer. To think dispassionately about what we design and why, as 
well as what the eventual consequences of our design intervention may be, is the basis of ethical thinking. Linked between values, creativity, beauty, art and the transcendental. (Papanek: 1999)

While "eco-fashion" concept is not selected to be taken further discussion and be a direction since the concept is more on eco-friendly concept that prioritizes eco-friendly design or production method or of which do not trigger nature damage. This concept is meant to find solutions of global warming, which has become the biggest phenome-non, as a sign that the planet earth is experiencing damage caused by various industry activities, including design and fashion which has been worsening.

Regarding environmental damage issues triggered by fashion industry, along with various latest world's phenomenon, discussions about fashion industry bad impacts are not merely about nature damage, but also social impact in the community where chronic consumerism appears as well as bad health and welfare issues of manufacture or garment producers' labors. These bad labor's welfare and health issues, even safety in fashion industry, is proven in an occurance where a building named Rana Plaza in Bangladesh was collapsed and take casualties of hundreds of the labors work inside the building. It occurs as the effect of the owner's ignorance and in general, from the entire fashion industry system in Bangladesh and other developing countries in Asia and Afrika as the producer in fashion industry where labors are paid with low wages.

Other eco-friendly concept has been discussed is "Sustainable Fashion". At the beginning of research, it was also mentioned that the research's direction is towards "Sustainable Fashion", since it was considered as the most comprehensive concept in formulating problem in fashion design and its solution. According to Sandy Black, sustainable fashion reflects the interdisciplinary nature of fashion's complex ethical and ecological dimensions - as manifested in the production, consumption, marketing and representation of fashion - which often conflicting priorities that need to be reconciled. (Black, 2012)

The sustainable fashion at frist seemed to be the most comprehensive and optimal solution for problems caused by the rapid grow of fashion industry. But after various studies performed, it is found that the concept does not fit to be applied in Indonesia, considering its community's social situation.

Based on observations performed in Indonesia, specifically in Bandung, Jakarta and Bali, and correlated with ecofriendly related theories in art, design and fashion, initial hypothesis is gained, that if it is related with Indonesian culture, therefore, the correct eco-friendly concept for fashion industry in Indonesia is ethical fashion. In ethical fashion there are economic, functional, aesthetics, safety and comfort values that a product shall have in general, and further it also shall have eco-friendly values, as well as social, ethical spiritual values contained in Bali culture.

Therefore, based on the mapping of correlation between product design - ecodesign - sustainable design and sustainable development by Kristel Dewulf and based on the above explanation, the conclusion is that conventional design or in general, design, contains economic, functional, aesthetics, safety values. However, if it is added by ecofriendly values (environmental issues), then it turns to be ecodesign. Further, if it is added by social or ethic value, then it becomes sustainable design. So that in sustainable design there are economic, functional, aesthetics, safety and comfort values that design products shall fulfill. In addition, in more comprehensive, also including eco-friendly, social and ethic values.

\section{References}

[1] Akib, Muhammad.. (2015) Penegakan Hukum Lingkungan dalam prospektif Holistik-Ekologis, Yogyakar-ta-Indonesia: Graha Ilmu

[2] Black, Sandy. (2012): The Sustainable fashion Handbook, London: Thames \& Hudson Ltd

[3] Brown, Sass. (2010): Eco Fesyen, United Kingdom, London: Lawrence King Publishing Ltd.

[4] Calasibetta, Charlotte Mankey \& Phyllis Tortora. (2003): Dictionary of Fesyen, London: Fairchild Publication Inc

[5] Dewulf, Kristel. (2013): "Sustainable Product Innovation: The Importance of the Front-End Stage in the In-novation Process", Book Chapter

[6] Eagan, Greta (2014): WEAR NO EVIL How to Change the World with Your Wardrobe, Running Press, Lon-don.

[7] Fletcher, Kate (2014): SUSTAINABLE FASHION AND TEXTILES, Design Journeys, Routledge, London

[8] Gordon, Jennifer Farley, Hill, Colleen. (2015): SUSTAINABLE FASHION Past, Present, and Future, Bloomsbury Academic, London

[9] Lucas, Dorian. (2013): Green Design Volume 1 \& 2: Braun

[10] Marianto, M Dwi. (2015): Art \& Levitation, Seni dalam Cakrawala Quantum. Yogyakarta - Indonesia: Pohon Cahaya

[11] Miles, Malcolm. (2014): Eco-aesthetics Art, Literature and Architecture in a Period of Climate Change, United Kingdom - London: Bloomburry Publishing

[12] Papanek, Victor. (1995): The Green Imperative: Ecology and Ethics in Design and Architecture. London: Thames and Hudson 